\title{
Remote sensing of ice crystal asymmetry parameter using multi-directional polarization measurements - Part 1: Methodology and evaluation with simulated measurements
}

\author{
B. van Diedenhoven ${ }^{1,2}$, B. Cairns ${ }^{2}$, I. V. Geogdzhayev ${ }^{3,2}$, A. M. Fridlind ${ }^{2}$, A. S. Ackerman ${ }^{2}$, P. Yang ${ }^{4}$, and B. A. Baum ${ }^{5}$ \\ ${ }^{1}$ Columbia University, Center for Climate System Research, New York, NY, USA \\ ${ }^{2}$ NASA Goddard Institute for Space Studies, New York, NY, USA \\ ${ }^{3}$ Columbia University, Department of Applied Physics and Applied Mathematics, New York, NY, USA \\ ${ }^{4}$ Texas A \& M University, Department of Atmospheric Sciences, College Station, TX, USA \\ ${ }^{5}$ Space Science and Engineering Center, University of Wisconsin-Madison, Madison, WI, USA
}

Correspondence to: B. van Diedenhoven (bastiaan.vandiedenhoven@nasa.gov)

Received: 25 May 2012 - Published in Atmos. Meas. Tech. Discuss.: 14 June 2012

Revised: 7 September 2012 - Accepted: 12 September 2012 - Published: 8 October 2012

\begin{abstract}
We present a new remote sensing technique to infer the average asymmetry parameter of ice crystals near cloud top from multi-directional polarization measurements. The method is based on previous findings that (a) complex aggregates of hexagonal crystals generally have scattering phase matrices resembling those of their components; and (b) scattering phase matrices systematically vary with aspect ratios of crystals and their degree of microscale surface roughness. Ice cloud asymmetry parameters are inferred from multi-directional polarized reflectance measurements by searching for the closest fit in a look-up table of simulated polarized reflectances computed for cloud layers that contain individual, randomly oriented hexagonal columns and plates with varying aspect ratios and roughness values. The asymmetry parameter of the hexagonal particle that leads to the best fit with the measurements is considered the retrieved value. For clouds with optical thickness less than 5, the cloud optical thickness must be retrieved simultaneously with the asymmetry parameter, while for optically thicker clouds the asymmetry parameter retrieval is independent of cloud optical thickness. Evaluation of the technique using simulated measurements based on the optical properties of a number of complex particles and their mixtures shows that the ice crystal asymmetry parameters are generally retrieved to within $5 \%$, or about 0.04 in absolute terms. The retrieval scheme is largely independent of calibration errors, range and sampling density of scattering angles and random noise in the
\end{abstract}

measurements. The approach can be applied to measurements of past, current and future airborne and satellite instruments that measure multi-directional polarized reflectances of ice-topped clouds.

\section{Introduction}

Cloud feedbacks remain among the principal sources of uncertainty in assessing the sensitivity of the Earth's climate (Hartmann et al., 1992; Soden and Held, 2006; Waliser et al., 2009). A continuing area of uncertainty in modeling clouds and consequently their feedbacks is prescribing the radiative properties of clouds and ice clouds ${ }^{1}$ in particular (Stephens et al., 1990; Stackhouse Jr. and Stephens, 1991; Fu et al., 1998; Fu, 2007). The fundamental radiative properties of ice clouds for global climate model projections can be represented in terms of optical thickness, effective ice crystal size and the first moment of the scattering phase function, commonly referred to as the asymmetry parameter (Coakley and Chylek, 1975; Fu and Liou, 1993; Yang et al., 2000; Fu, 2007). Reasonably stringent global constraints of two of these three parameters, namely ice cloud optical thickness and effective ice crystal size, have been obtained for more than three decades from measurements of

\footnotetext{
${ }^{1}$ We use "ice clouds" as shorthand for all clouds that have tops which are radiatively dominated by ice.
} 
instruments on polar-orbiting and geostationary satellite platforms, such as the Moderate Resolution Imaging Spectroradiometer (MODIS, Platnick et al., 2003), the Geostationary Operational Environmental Satellite (GOES, Lindsey and Grasso, 2009) and the Spinning Enhanced Visible and Infrared Imager (SEVIRI, Roebeling et al., 2006). However, to our knowledge, no remote sensing technique exists to date to directly infer the asymmetry parameter of ice crystals. Such measurements are crucial to better constrain values used for climate models. Vogelmann and Ackerman (1995) estimated that asymmetry parameters must be known to within 2-5\% to constrain computed shortwave fluxes to within about $5 \%$. Furthermore, a remote sensing technique to obtain ice asymmetry parameter could help to improve operational retrievals of ice cloud optical thickness and effective radius, which substantially depend on the scattering properties of the ice crystal model used in the retrieval algorithms (Rolland et al., 2000; Yang et al., 2008a; Zhang et al., 2009; Baum et al., 2011; van Diedenhoven et al., 2012).

Ice crystal asymmetry parameters at visible wavelengths have been inferred indirectly from combinations of flux measurements and radiative transfer model calculations (e.g., Platt et al., 1980; Stephens et al., 1990; Francis et al., 1994; Mitchell et al., 1996), yielding values ranging from about 0.7 to about 0.85 . More direct in situ measurements made with the Cloud Integrating Nephelometer (CIN, Gerber et al., 2000) and the Polar Nephelometer (Gayet et al., 1997) generally show values around 0.75 , with little dependence on location and temperature (e.g., Auriol et al., 2001; Garrett et al., 2001, 2003, 2005; Baran et al., 2005; Gayet et al., 2006, 2012, see Garrett, 2008 for an overview). However, these in situ observed asymmetry parameters provide poor spatial coverage and may be substantially affected by ice shattering on the probes (Korolev et al., 2011), or undersampling of the phase function in the forward scattering direction (Gerber et al., 2000), or both. Global polarization measurements from the Polarization and Directionality of the Earth's Reflectances (POLDER) instrument are generally found to be consistent with roughened ice crystals, which in turn generally have relatively low asymmetry parameters $(<0.8)$. In contrast, using surface observations, Sassen et al. (2003) reported frequent sightings of halos within ice clouds that imply pristine ice crystals, which generally have high asymmetry parameters.

Theoretical ice scattering properties have been calculated for a wide range of particle shapes (e.g., Macke et al., 1996; Hess et al., 1998; Yang and Liou, 1998; Zhang et al., 2004; Liu et al., 2006; Um and McFarquhar, 2007, 2009, 2011; Nousiainen et al., 2011; Baum et al., 2011; Ishimoto et al., 2012), yielding asymmetry parameters ranging from about 0.65 to above 0.95 . General conclusions that can be deduced from these theoretical studies are: (1) complex aggregates of crystals generally have scattering phase matrices resembling those of their components (e.g., Fu, 2007; Um and McFarquhar, 2007, 2009); and (2) scattering phase matrices systematically vary with aspect ratios (ratio of length to width) of crystals (or crystal components in aggregates) and their degree of randomization (e.g., Fu, 2007; Yang and Fu, 2009). For pristine, simple particles, such as smooth hexagonal columns, the phase function often shows strongly contrasted features such as halos that are the created by ray caustics (Minnaert, 1954). Such features can be suppressed by increasing microscale crystal surface roughness (Macke et al., 1996), increasing the number of impurities within ice crystals (Hess et al., 1998), or increasing large-scale complexity of ice aggregates (Ishimoto et al., 2012).

Based on the two aforementioned generalizations of ice crystal scattering properties, here we present a remote sensing technique to infer ice crystal asymmetry parameter from multi-directional polarization measurements. In short, by assuming individual hexagonal ice columns and plates to serve as proxies for more complex shapes and aggregates, a best fit to multi-directional polarization measurements is sought by varying the aspect ratios and roughness parameters of columns and plates, and the asymmetry parameter of the corresponding hexagonal column or plate is considered to be representative (i.e., the retrieved value) of the asymmetry parameter of the ice crystal ensemble at the top of the observed cloud.

Several attempts have been made previously to deduce ice crystal shape from polarization measurements, mostly applied to measurements of the Polarization and Directionality of the Earth's Reflectances (POLDER) instrument (e.g., Chepfer, 1998; C.-Labonnote et al., 2000; Chepfer et al., 2001; Masuda et al., 2002; Knap et al., 2005; Sun et al., 2006; Baran and C.-Labonnote, 2006). Most of these attempts included only a limited collection of ice crystal habits and/or aspect ratios and many of them did not include roughened ice crystals. To our knowledge, our application is the first to include a virtually continuous selection of aspect ratios and roughness values. Moreover, while previous results were difficult to relate to physical and radiative properties of ice crystals, here we directly relate the retrieved particle aspect ratio and roughness parameter to the ice crystal asymmetry parameter. A similar approach was recently applied to a subvisual cirrus cloud (Ottaviani et al., 2012a) and thick tropical clouds (van Diedenhoven et al., 2012), as well as over a snow surface (Ottaviani et al., 2012b).

Here in Part 1 of a two-part paper, the retrieval method is described and evaluated using simulated measurements. The simulated measurements are based on instrument characteristics of the airborne Research Scanning Polarimeter (RSP, Cairns et al., 1999). In Part 2 we apply the method to measurements obtained by RSP during the The Cirrus Regional Study of Tropical Anvils and Cirrus Layers - Florida Area Cirrus Experiment (CRYSTAL-FACE) and evaluate results using other remote sensing and in situ data.

First, the retrieval method is presented in detail in Sect. 2. After evaluating the method against simulated measurements in Sect. 3, conclusions are discussed in Sect. 4. 


\section{Methodology}

The asymmetry parameter $g$ is defined as the first moment of the normalized scattering phase function $P_{\text {tot }}$ (Macke et al., 1996):

$g=\int_{0}^{\pi} P_{\text {tot }}(\Theta) \cos (\Theta) \sin (\Theta) \mathrm{d} \Theta$,

where $\Theta$ is scattering angle. In the geometric optics regime the asymmetry parameter is a linear combination of the asymmetry parameters of the refractive + reflective and diffractive contributions to the phase function, $g_{\text {ref }}$ and $g_{\text {dif }}$, respectively (Macke et al., 1996):

$g=\frac{1}{2 \omega_{0}}\left[\left(2 \omega_{0}-1\right) g_{\text {ref }}+g_{\text {dif }}\right]$,

where $\omega_{0}$ is the single scattering albedo, which is mainly determined by the ice effective radius and the imaginary part of the refractive index (Mitchell and Arnott, 1994; Fu et al., 1998). The asymmetry parameter of the diffractive contribution to the phase function is essentially unity for ice clouds at visible and shortwave infrared wavelengths as a consequence of particles being large relative to wavelength. The refractive + reflective contribution to the phase function depends on the shape of the ice particles and their microscale surface roughness (Macke et al., 1996; Yang and Liou, 1998). As explained above, we adopt hexagonal ice columns and plates with varying aspect ratio and microscale roughness as proxies for more complex shapes and aggregates to infer the asymmetry parameter. Together with ice crystal effective radius (e.g., Nakajima and King, 1990), the total asymmetry parameter can be estimated for any wavelength using Eq. (2).

Ice crystal asymmetry parameters are inferred from measured polarized reflectances $R_{\mathrm{p}}$ defined as

$R_{\mathrm{p}}=\frac{\pi \sqrt{Q^{2}+U^{2}}}{\mu_{0} F_{\odot}}$,

where $\mu_{0}$ is the cosine of the solar zenith angle, $F_{\odot}$ is the solar irradiance, and $Q$ and $U$ are the second and third Stokes parameters, respectively (van de Hulst, 1957; Chepfer, 1998; Baran and C.-Labonnote, 2006). To produce a look-up table (LUT) containing $R_{\mathrm{p}}$ values for clouds consisting of hexagonal plates and columns with varying aspect ratios and roughness parameters, forward calculations are made using a plane-parallel doubling-adding code (Hansen and Travis, 1974; De Haan et al., 1987). The cloud is represented in the model by a single uniform layer without considering cloud geometrical thickness. Rayleigh scatterers and absorbing atmospheric gases are not included. Randomly oriented ice crystals are assumed (Bréon and Dubrulle, 2004; Zhou et al., 2012). To account for the highly peaked scattering phase functions, we use the $\delta-M$ approximation (Wiscombe,
1977) for multiple-scattered light, whereas the contribution of single-scattered light is calculated analytically (using the TMS-method described by Nakajima and Tanaka, 1988). A completely black, non-polarizing surface is assumed for the lower boundary condition. For thin cirrus (with optical thickness less than about 1), the influence of polarized surface reflectance at visible wavelengths could be significant and should be included in the forward model when applying the presented method to real measurements. Accurate models exist for ocean reflectances (e.g., Chowdhary et al., 2012) and land surface reflectances (e.g., Litvinov et al., 2010).

To produce the LUT, a database of optical properties for hexagonal plates and columns is calculated using the Geometrics Optics (GO) code developed by Macke et al. (1996). This ray tracing code takes microscale surface roughness of ice crystals into account in a statistical manner by perturbing, for each interaction with a ray, the normal of the crystal surface from its nominal orientation by an angle varied randomly with uniform distribution between $0^{\circ}$ and $\delta \cdot 90^{\circ}$, where $\delta$ is referred to as the roughness parameter (see Macke et al., 1996, for a full description of the treatment of roughness). Yang et al. (2008b) found that this approach is an efficient, yet accurate treatment of microscale roughness. The aspect ratio of columns is varied between 1 and 50 with 26 geometrically increasing steps. The aspect ratios of plates are the inverse of those for columns, for a total of 51 aspect ratios. The roughness parameter is varied between 0 and 0.7 in steps of 0.05 . Roughness parameters exceeding 0.7 are not considered because for these values the probability of unphysical scattering events strongly increases, resulting in progressively larger loss of accuracy of the GO calculations of a given number of rays. The database could be expanded with more extreme aspect ratios and greater roughness parameters in the future if deemed necessary. Sizes are varied so that the projected areas of the particles, assuming random orientation, correspond to the projected areas of spheres with radii of $5,7,10,14,20,28,40,56,80,113,160,226$ and $320 \mu \mathrm{m}$. A normalized gamma size distribution $N$ of the form

$N(D)=N_{0} D^{\mu_{\mathrm{p}}} e^{-\lambda_{\mathrm{p}} D}$

is applied (Mitchell, 1991; Heymsfield et al., 2002), where $D$ is the maximum particle dimension and $\mu_{\mathrm{p}}$ and $\lambda_{\mathrm{p}}$ are the shape and slope parameters of the size distribution. Here, $N_{0}$ is a normalization factor. For some of the considered combinations of size and aspect ratio, the size parameters of the particles are outside the range where the geometric optics approximation is valid (Mishchenko and Macke, 1999); possible implications of this are discussed in Sect. 3.2. Refractive indices for ice are taken from Warren and Brandt (2008) and are weighted by spectral response function of RSP's 864-nm channel and the incoming solar spectrum, yielding a refractive index of 1.3038 with a negligible imaginary part.

Figure 1 shows the asymmetry parameter of the phase function of hexagonal plates and columns in the database 


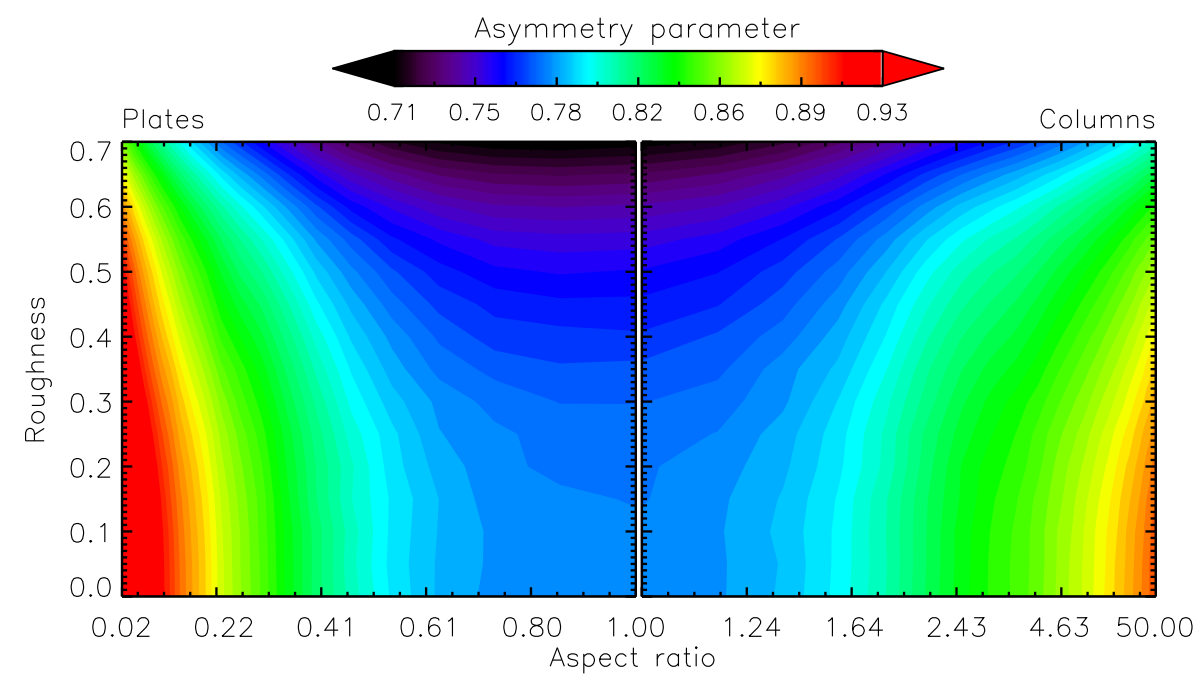

Fig. 1. Asymmetry parameters of plates and columns at $864 \mathrm{~nm}$ as a function of their aspect ratio and microscale roughness.

as a function of aspect ratio and roughness parameter. Here, $\mu_{\mathrm{p}}=1.5$ and $\lambda_{\mathrm{p}}=100 \mathrm{~cm}^{-1}$ (Heymsfield et al., 2002), but we note that the asymmetry parameter is not affected substantially by the size in the geometric optics regime (Macke et al., 1996). As previously shown by Macke et al. (1996), $\mathrm{Fu}$ (2007), Yang and Fu (2009) and others, the asymmetry parameter increases with increasing deviation of the aspect ratio from unity, and decreases with increasing roughness. Thus, the lowest asymmetry parameters around 0.71 are obtained for particles with an aspect ratio of unity and extreme roughness of 0.7 , while asymmetry parameters exceeding 0.93 are found for smooth thin plates with aspect ratios near 0.02 . Asymmetry parameters increase with aspect ratio owing to the increase of parallel surface areas, leading to greater probability of light passing through the particle with low orders of refraction + reflection and a minimal change of direction (Yang and $\mathrm{Fu}, 2009$ ). For the same reason, the increase of asymmetry parameter with increasing deviation of aspect ratio from unity is slightly weaker for columns than for plates owing to the larger parallel surfaces of plates (cf. Macke et al., 1996; Yang and Fu, 2009).

Figure 2 illustrates the dependence of the single scattering degree of linear polarization (DoLP) function on aspect ratio and roughness parameter of hexagonal columns. Here, DoLP is defined as $P_{12} / P_{11}$, where $P_{12}$ and $P_{11}$ are the corresponding elements of the scattering phase matrix (see e.g., Macke et al., 1996). The dependence of the DoLP function of plates on both aspect ratio and roughness parameter is similar to that of columns (not shown). As noted by Knap et al. (2005), Baran and C.-Labonnote (2006) and others, the DoLP function for randomly oriented smooth columns shows positive features at scattering angles around $130^{\circ}$ and negative values at scattering angles larger than $160^{\circ}$, while these features decrease in strength or disappear completely with an increasing roughness parameter (Fig. 2b). Similar dependence of the DoLP function on roughness has been reported for more complex particles by Um and McFarquhar (2009) and Baum et al. (2010), among others. As seen in Fig. 2a, the DoLP function of a slightly roughened column increases with increasing aspect ratio, especially at scattering angles smaller than about $140^{\circ}$ (cf. Chepfer, 1998). Figure 3 shows similar variations in DoLP functions for various moderately roughened complex habits (Yang et al., 2012, see also Sect. 3.2). In the range of scattering angles typically observed by downward looking remote sensing instruments (about $90-175^{\circ}$ depending on geometry), the DoLP shows distinctively different variations (Fig. 2) as a function of aspect ratio and roughness parameter. This suggests that these two parameters can be estimated from such polarization measurements and that, as a consequence (cf. Fig. 1), the asymmetry parameter can be inferred.

For the inference of ice crystal asymmetry parameter, we aim to minimize the relative root-mean-squared difference (RRMSD) between polarization measurements at the considered angles and the corresponding simulated values from our look-up table. For a given combination of aspect ratio $\mathrm{AR}_{i}$ and roughness parameter $\delta_{j}$, the RRMSD is formally defined as

$\operatorname{RRMSD}\left(\mathrm{AR}_{i}, \delta_{j}\right)=\sqrt{\frac{\sum_{n=1}^{N}\left[1-\frac{R_{\mathrm{p}, \mathrm{LUT}}\left(\Theta_{n}, \mathrm{AR}_{i}, \delta_{j}\right)}{R_{\mathrm{p}, \text { meas }}\left(\Theta_{n}\right)}\right.}{N}}$

where $R_{\mathrm{p} \text {, meas }}$ is the measured polarized reflectance as a function of single scattering angle $\Theta$, and $R_{\mathrm{p}}$, LUT is the corresponding quantity in the LUT. In the current retrieval approach, the RRMSD is simply calculated for all combinations of aspect ratios and roughness parameters that are included in the LUT and the retrieved values correspond to the minimum value of the RRMSD. To optimize such 


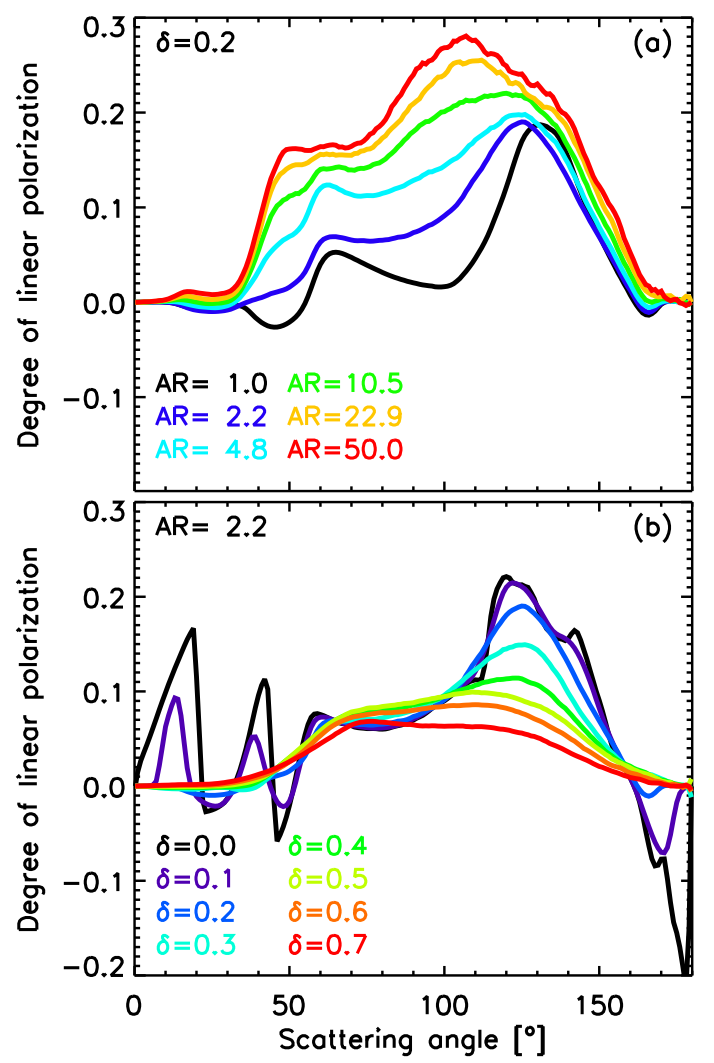

Fig. 2. Degree of linear polarization at $864 \mathrm{~nm}$ as a function of scattering angle for hexagonal columns. Colors indicate DoLP functions for varying aspect ratios (AR, a) and roughness parameters $(\delta, \mathbf{b})$.

a retrieval, more efficient minimization approaches could be used (Rodgers, 2000).

For cloud optical thicknesses $\tau_{\text {cloud }}$ larger than about 5 , the polarized reflectance saturates and does not depend on $\tau_{\text {cloud }}$ (Chepfer et al., 2001). For optically thinner clouds, the LUT must also include the correct apparent cloud optical thickness (apparent cloud optical thickness is defined as the optical thickness yielding a total reflectance that matches measurements under the assumption of a particular ice model). Since the apparent optical thickness also depends on the assumed ice asymmetry parameter (Zhang et al., 2009), it needs to be determined for all aspect ratio and roughness combinations in the LUT before applying Eq. (5). Here, we obtain the apparent optical thickness by minimizing the differences between measured and simulated total reflectances at $864 \mathrm{~nm}$ at the viewing angle closest to nadir. For cases with $\tau_{\text {cloud }} \geq 5$, the asymmetry parameter can be retrieved using Eq. (5) assuming a large cloud optical thickness (e.g., $\tau_{\text {cloud }}=50$ ), and the correct cloud optical thickness can be determined afterwards. Whether $\tau_{\text {cloud }}$ is above or below five is estimated by using threshold values of total reflectance generated by a first-guess ice model.

We use polarized reflectance rather than measurements of degree of polarization to retrieve asymmetry parameters

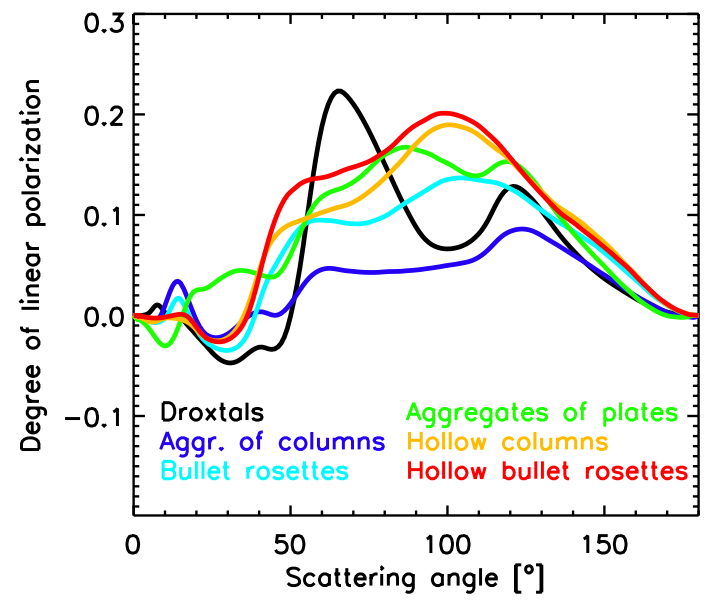

Fig. 3. Similar to Fig. 2 but for various moderately roughened complex ice habits.

because for thick clouds it is independent of cloud optical thickness. Furthermore, for thin clouds, the degree of polarization can be highly sensitive to the total bidirectional reflectance function of the surface, which is not always known well. However, the retrieval results presented in the next section are found to be very similar when using degree of polarization instead of polarized reflectance (not shown).

\section{Results}

The retrieval approach is evaluated here by applying it to synthetic measurements. These synthetic measurements are calculated using the radiative transfer model described in the previous section, but using optical properties of ice crystals with more complex shapes than the individual columns and plates assumed in the LUT. We aim to infer the asymmetry parameters of the complex ice crystals to within $5 \%$ (or $\sim 0.04$ ), which is the upper range of the required accuracy of global ice cloud asymmetry parameter estimated by Vogelmann and Ackerman (1995).

A solar zenith angle of $41^{\circ}$ and relative azimuth angle of $10^{\circ}$ is used for the simulated measurements (corresponding to some of the RSP data used in part 2). RSP measures at 152 viewing angles between $\pm 60^{\circ}$. In the following, we limit the measurements to contain scattering angles in the range 100$165^{\circ}$, which are frequently observed by RSP. The sampling of scattering angles of the RSP at this geometry is about $0.8^{\circ}$. Simulations are made for the $864 \mathrm{~nm}$ band of RSP, but similar results are expected at wavelengths from the visible to shortwave infrared since scattering in ice clouds is relatively independent of wavelength. For the same reason, addition of other wavelengths is not expected to improve the results. First, we apply the proposed retrieval approach to simulated measurements assuming clouds consisting of bullet rosettes, other complex habits and mixtures of complex habits. Then, 


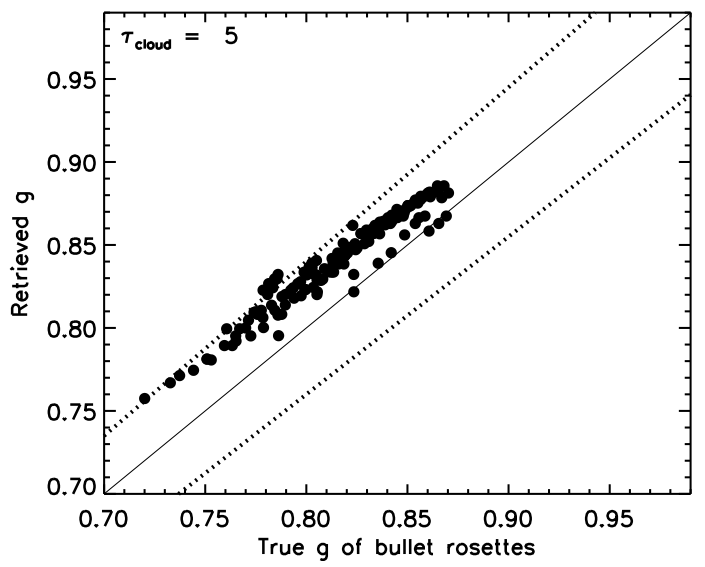

Fig. 4. Asymmetry parameters of bullet rosettes versus the asymmetry parameters retrieved with the proposed method from simulated data with a cloud optical thickness of 5 . The solid line shows the 1-1 line. Dotted lines indicate the targeted $5 \%$ accuracy limits.

the sensitivity of the method to measurements noise, calibration errors, the available scattering angle range and the angular sampling is explored.

\subsection{Bullet rosettes}

Ice crystals resembling bullet rosettes are often observed in mid-latitude cirrus and aged anvil cirrus clouds (Iaquinta et al., 1995; Lawson et al., 2006; Um and McFarquhar, 2007; Baran, 2009; Baum et al., 2011). Optical properties of bullet rosettes are calculated using the same GO code described above (Macke et al., 1996). Following Um and McFarquhar (2007), bullet rosettes are constructed with 6 identical branches consisting of 13 planes each with a bullet tip angle of $28^{\circ}$. Ten different bullet aspect ratios between 2 and 11 are considered, where aspect ratio is defined as the ratio of the total bullet length (including tip) and its width. As with the hexagonal ice crystals used in the LUT, the roughness parameter varies between 0 and 0.7 in steps of 0.05 . Projected areas cannot be analytically calculated for bullet rosettes and we therefore calculated the scattering properties of bullet rosettes that have volumes that are the same as spheres with radii of $5,7,10,14,20,28,40,56,80,113$, 160,225 and $320 \mu \mathrm{m}$. This volume equivalent spherical size definition is different to the projected area definition that was used in Sect. 2. Since the results do not substantially depend on size distribution, because the bullet geometry does not vary with size, we nonetheless use the same size distribution that was introduced in Sect. 2. A total of 150 combinations of roughness parameter and bullet aspect ratio is included in the sample.

Figure 4 shows the asymmetry parameters of the bullet rosettes versus those retrieved from the simulated $R_{\mathrm{p}}$ using the proposed method. Here, a cloud optical thickness of 5 is assumed in the simulated measurements. Retrieved values

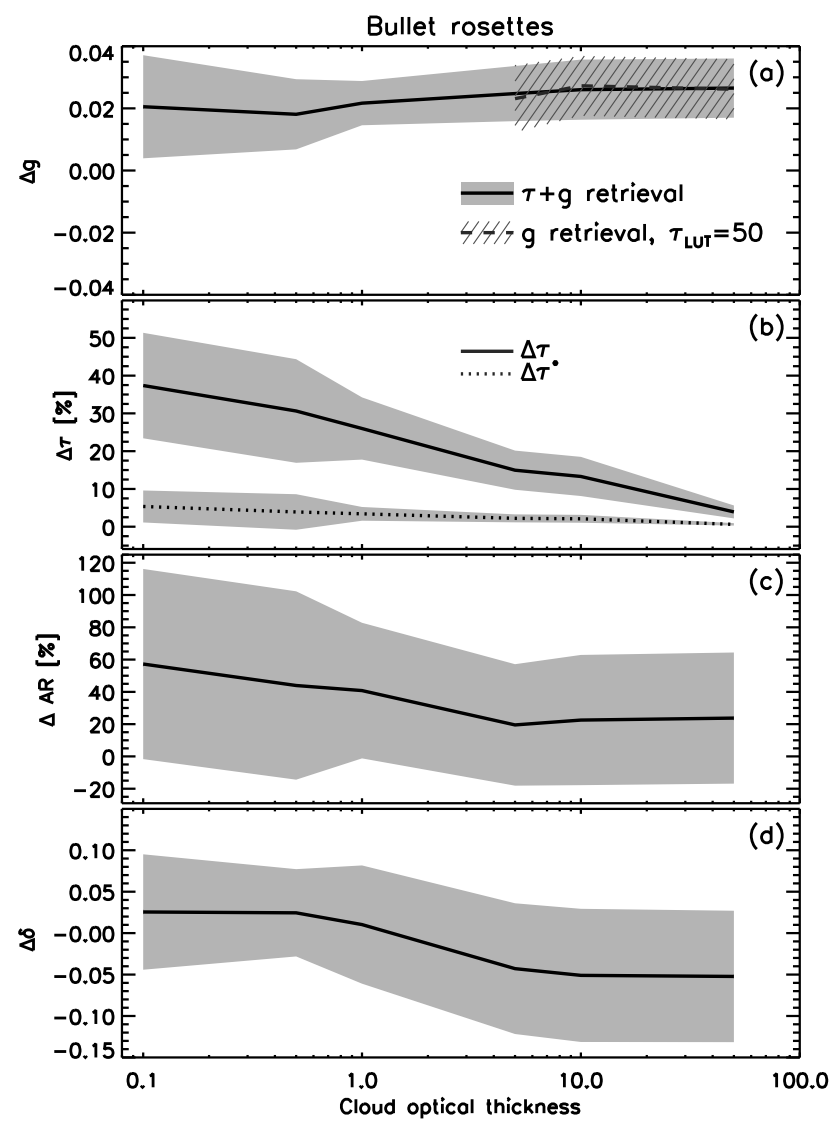

Fig. 5. Mean biases (solid lines) and standard deviations (shaded areas) of retrieved asymmetry parameters (a), optical thickness (b), aspect ratio (c) and roughness parameter (d) as a function of cloud optical thickness assumed in the simulated data using bullet rosettes. The dashed line and line-shaded area in (a) shows results where $\tau_{\text {cloud }}=50$ is assumed in the LUT. The dotted line in (b) shows the mean bias of the scaled optical thickness (defined in text).

are generally within $5 \%$ of the true values, although they are biased high, especially for small asymmetry parameters. Figure 5a shows the mean differences between retrieved and true asymmetry parameters and their standard deviations as a function of cloud optical thickness. Generally, results are quite consistent over all optical thickness values with mean biases of about $0.02 \pm 0.01$, with the second number representing the standard deviation. Slightly larger standard deviations are obtained for optically thin clouds. In these retrievals the apparent cloud optical thickness is determined first before retrieving the asymmetry parameter. As discussed in Sect. 2 , when $\tau_{\text {cloud }} \gtrsim 5$, polarized reflectances are considered to be saturated and asymmetry parameters can be retrieved by applying Eq. (5) and assuming any large cloud optical thickness. To illustrate this, Fig. 5a also shows results of retrieved asymmetry parameters for $\tau_{\text {cloud }} \geq 5$ using the LUT with $\tau_{\text {cloud }}=50$. These results are seen to be similar to those in which $\tau_{\text {cloud }}$ is retrieved simultaneously with the asymmetry parameter. 
The bias in retrieved asymmetry parameter leads to a 10 $40 \%$ bias in retrieved cloud optical thickness, especially for optically thin clouds (Fig. 5b). However, the bias in scaled optical thickness $\tau^{*}=\tau(1-g)$ (van de Hulst, 1957; King, 1987) is much smaller, as expected (Zhang et al., 2009). Figure $5 \mathrm{c}$ shows that mean differences between aspect ratios of the individual bullets and retrieved values are about $20 \pm 40 \%$ for $\tau_{\text {cloud }}>5$, but increase to $60 \pm 50 \%$ for optically thinner clouds. The crystals are consistently retrieved as column-like. Biases in retrieved roughness parameter shown in Fig. $5 d$ are about $-0.05 \pm 0.08$ for clouds with $\tau_{\text {cloud }}>5$ and about $0.03 \pm 0.08$ for $\tau_{\text {cloud }}<5$. The general positive bias of retrieved asymmetry parameters is consistent with the findings of Um and McFarquhar (2007) that the asymmetry parameters of bullet rosettes are about $2 \%$ lower than those of the individual bullets, presumably owing to the increased variation in refraction + reflection angle combinations in the more complex rosettes versus those in the individual bullets (cf. Macke et al., 1996). This effect is apparently only partly mitigated by the effect of biases in aspect ratio and roughness parameter in the retrievals.

\subsection{Complex habits}

Next we apply the proposed method to simulated measurements assuming a selection of hexagonal and complex ice crystal habits: droxtals (Zhang et al., 2004), columns, plates, bullet rosettes, aggregates of columns, hollow columns (Yang and Liou, 1998), hollow bullet rosettes (Yang et al., 2008c) and aggregates of plates (Baum et al., 2011). Details about the geometries of these crystals are given in the cited references. The scattering properties of the individual particles are computed using the discrete dipole approximation (DDA) for particles with a small size parameter (defined as the ratio of the particle circumference to the incident wavelength) or an improved geometric optics method (IGOM) for particles with a large size parameter (Yang and Liou, 1998; Bi et al., 2009; Xie et al., 2011; Yang et al., 2012). Microscale crystal surface roughness is taken into account with an approximate method similar to that in the GO code described in Sect. 2 (Yang et al., 2008a). As in Baum et al. (2011), smooth, moderately roughened and severely roughened particles are considered with a degree of surface roughness $\sigma$ of $0,0.03$ and 0.5 , respectively (see Yang et al., 2008a, for the definition of $\sigma$ ). Since some of the ice habit geometries vary with size, a range of size distributions is applied by varying $\lambda_{\mathrm{p}}$ in Eq. (4) from 20 to $200 \mathrm{~cm}^{-1}$ with increments of $20 \mathrm{~cm}^{-1}$ and using the relation between $\mu_{\mathrm{p}}$ and $\lambda_{\mathrm{p}}$ determined by Heymsfield et al. (2002) from in situ measured ice size distributions, namely $\mu_{\mathrm{p}}=\lambda_{\mathrm{p}}^{0.64}-2$ (with $\lambda_{\mathrm{p}}$ in units of $\left.\mathrm{cm}^{-1}\right)$. A total of 270 combinations of habit, roughness and size are included in the sample.

For a cloud optical thickness of 5, retrieved asymmetry parameters are seen in Fig. 6 to be highly correlated with the true values, with a mean bias of $0.004 \pm 0.018$. For particle

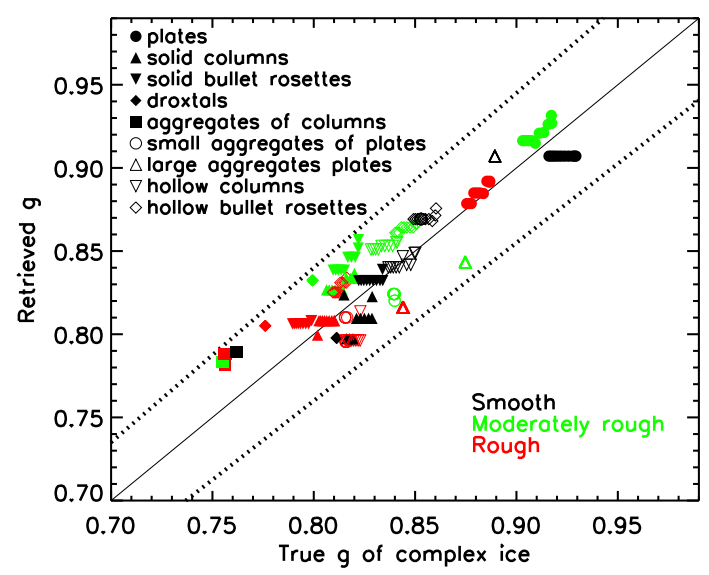

Fig. 6. As for Fig. 4, but for simulated data assuming various ice crystal habits indicated by symbols. Black, green and red colors are results for simulated data assuming smooth, moderately rough, and severely rough particles, respectively. For each combination of roughness and habit, 10 different size distributions are applied (see text).

shapes with geometries independent of size, which is the case for aggregates and droxtals, the results for different size distributions are clustered together. The biases and standard deviations are seen in Fig. 7a to be nearly independent of cloud optical thickness. Furthermore, the biases in the retrievals are significantly smaller than those obtained for the case of bullet rosettes (Fig. 5), but the standard deviations are greater. Plates and their aggregates are generally identified correctly as plates in the retrieval. Even when the habit is misinterpreted as being thin columns for some combinations of size and roughness, the retrieved asymmetry parameters still agree with the true values within $5 \%$. The other particles are consistently and correctly identified as column-like. Interestingly, the method finds that the polarized reflectances of clouds consisting of hollow columns and hollow bullet rosettes most closely resemble those consisting of columns with high aspect ratio $(>15)$. This result makes sense since the walls of the hollow parts of the crystals are thin, resembling columns with high aspect ratios. For all particles the retrieved roughness parameters increase with increasing roughness of the particles assumed in the simulated measurements, as expected. Mean biases in the retrieved cloud optical thickness, shown in Fig. $7 \mathrm{~b}$, are near zero for $\tau_{\text {cloud }}>5$, with standard deviations of about $10 \%$, while for thin cloud $\left(\tau_{\text {cloud }} \sim 1\right)$ the cloud optical thickness is retrieved within about $15 \pm 25 \%$. As found for the simulated measurements assuming bullet rosettes (Fig. 5b), the mean bias in scaled optical thickness is near zero for all cloud optical thickness values.

Possibly, part of the bias and standard deviation in retrieved asymmetry parameter may be caused by the use of standard GO calculations for the LUT while the optical properties used for the simulated measurements are calculated 


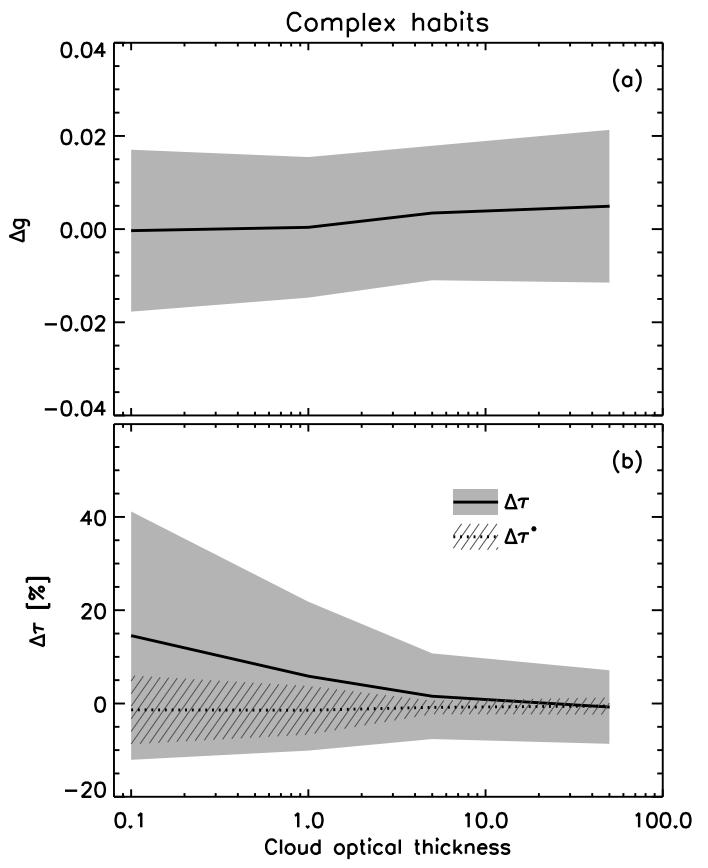

Fig. 7. Mean biases (solid lines) and standard deviations (shaded areas) of retrieved asymmetry parameters (a), optical thickness (b) as a function of cloud optical thickness assumed in the simulated data using complex habits. The dotted line and line-shaded area in (b) shows the mean bias and standard deviation, respectively, of the scaled optical thickness.

with the more accurate IGOM approach in combination with DDA. Future work is needed to investigate whether biases and standard deviation will be reduced by implementing more accurate optical properties for the LUT calculations.

\subsection{Habit mixtures}

The proposed method is next applied to simulated measurements using optical properties of mixtures of ice crystal habits. We use mixtures compiled by Baum et al. (2005a,b, 2011) to be consistent with ice water contents and median mass diameters measured by in situ probes during numerous field campaigns. The mixtures consist of combinations of the hexagonal and complex habits described in Sect. 3.3 and the same three degrees of crystal roughness are used. Four mixtures are considered: the general habit mixture compiled for the MODIS collection-5 ice properties retrieval algorithm (Baum et al., 2005a,b), a more recent general habit mixture (Baum et al., 2011), and those corresponding to tropical deep convection clouds and mid-latitude cirrus (Baum et al., 2011). A total of 120 combinations of habit mixture, roughness and size is included in the sample.

In Fig. 8 it is seen that asymmetry parameters of the particle mixtures span from 0.8 to about 0.87 , and most asymmetry parameters are again retrieved within $5 \%$. However, asymmetry parameters for the tropical deep convection

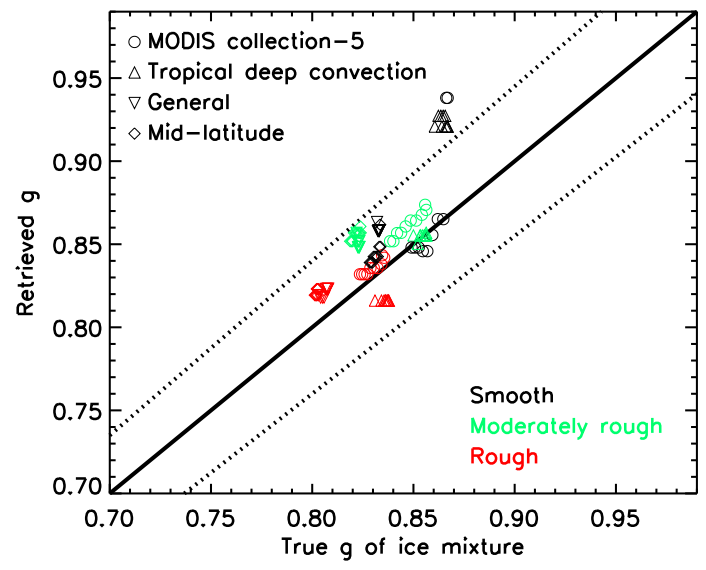

Fig. 8. As for Fig. 6, but for simulated data assuming various ice crystal habit mixtures. Circles denote the MODIS collection-5 mixture of Baum et al. (2005a,b) and the other symbols denote mixtures of Baum et al. (2011).

mixture, which is dominated by aggregates of plates, are systematically overestimated by about 0.05 when no roughness is applied. The retrieval algorithm interprets these mixtures as very thin plates with aspect ratios less than 0.1 . The same is true for three results for smooth collection-5 mixtures with large sizes, which are dominated by bullet rosettes, columns and plates. Thus, when smooth, very thin plates are retrieved by the algorithm, such retrieved asymmetry parameters should be treated with caution and probably rejected.

As for the complex habits (Fig. 7), the bias of the retrieved asymmetry parameter of the particle mixtures is slightly positive and fairly independent of the cloud optical thickness (Fig. 9a). Also, again, the retrieved cloud optical thickness is biased towards greater values (Fig. 9b), but essentially no bias is obtained in the retrieval of scaled optical thickness.

\subsection{Sensitivity to noise, calibration, angular range and sampling}

Next, the sensitivity of the asymmetry parameter retrieval approach to random noise, calibration errors and the available scattering angles are evaluated. For this analysis, we use the simulated measurements assuming optical properties of complex habits described in Sect. 3.2.

Pseudo-random structures can appear on the multi-angle total and polarized reflectance measurements owing to, for example, instrument noise, errors in stray-light correction and misalignment of scenes targeted at different angles (Cairns et al., 2003; Fougnie et al., 2007). Such errors are estimated to be of the order of $3 \%$ for instruments such as POLDER (Fougnie et al., 2007) and lower for the RSP (Cairns et al., 2003). To investigate the influence of such errors on our retrieval of asymmetry parameters, we add Gaussian noise with increasing standard deviation to simulated data. As seen in Fig. 10a, the bias and standard deviation 


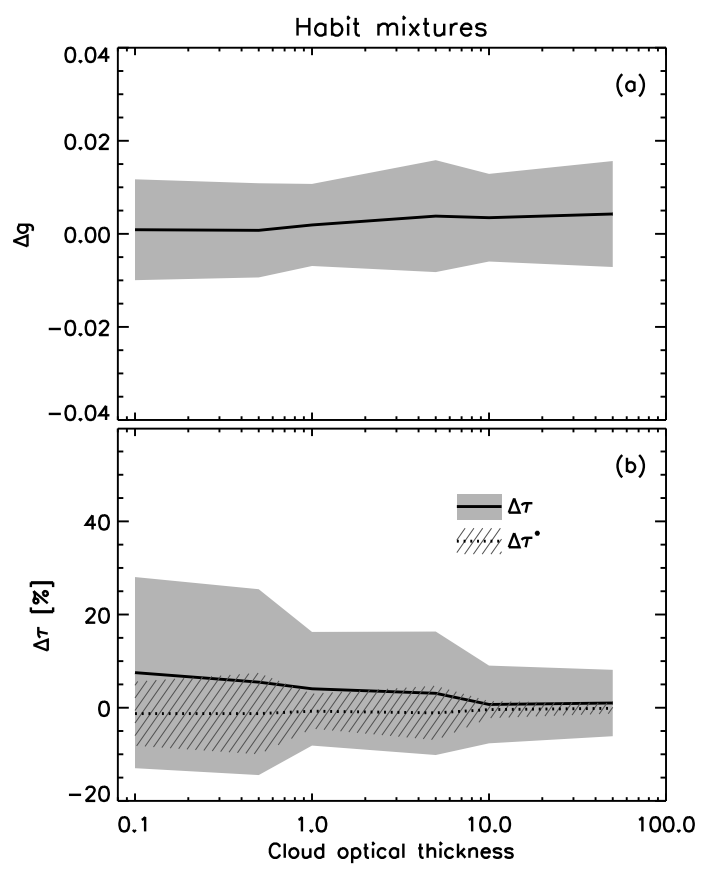

Fig. 9. As for Fig. 7, but for simulated data assuming various ice crystal habit mixtures.

are essentially unaffected by random noise with standard deviations of up to about $20 \%$ of the signal. For noise contributions larger than a threshold of about $20 \%$, the retrieval results rapidly degrade. Note that these simulations assume the angular sampling corresponding to the RSP, which, for the assumed geometry, lead to 84 samples within the 100$160^{\circ}$ scattering angle range considered. Since the influence of Gaussian noise is expected to scale as $\sqrt{N_{\mathrm{s}}}$, where $N_{\mathrm{s}}$ is the number of sampling points, requirements of measurements of instruments with less angular sampling will be more stringent than those for the RSP. For example, POLDER has about 10 times fewer viewing angles than the RSP, requiring the noise level to be about $\sqrt{10}$ times lower or a threshold of about $6 \%$. Note that POLDER generally is expected to meet this requirement (Fougnie et al., 2007).

Determination of the absolute calibration of instruments measuring total and polarized reflectance can be challenging, especially with the absence of on-board calibration sources and with aircraft-mounted instruments that undergo frequent and substantial changes in temperature, humidity, among others. The nearly linear dependence seen in Fig. 10b indicates that every additional $10 \%$ calibration offset added to the simulated data leads to an additional 0.003 near-linear increase in bias for the retrieved asymmetry parameter. Furthermore, the standard deviation increases by about 0.002 for every additional $10 \%$ offset. Since most calibration errors are expected to equally affect total and polarized reflectance measurements, offsets are added to both total and polarized reflectances here. However, similar results are obtained when
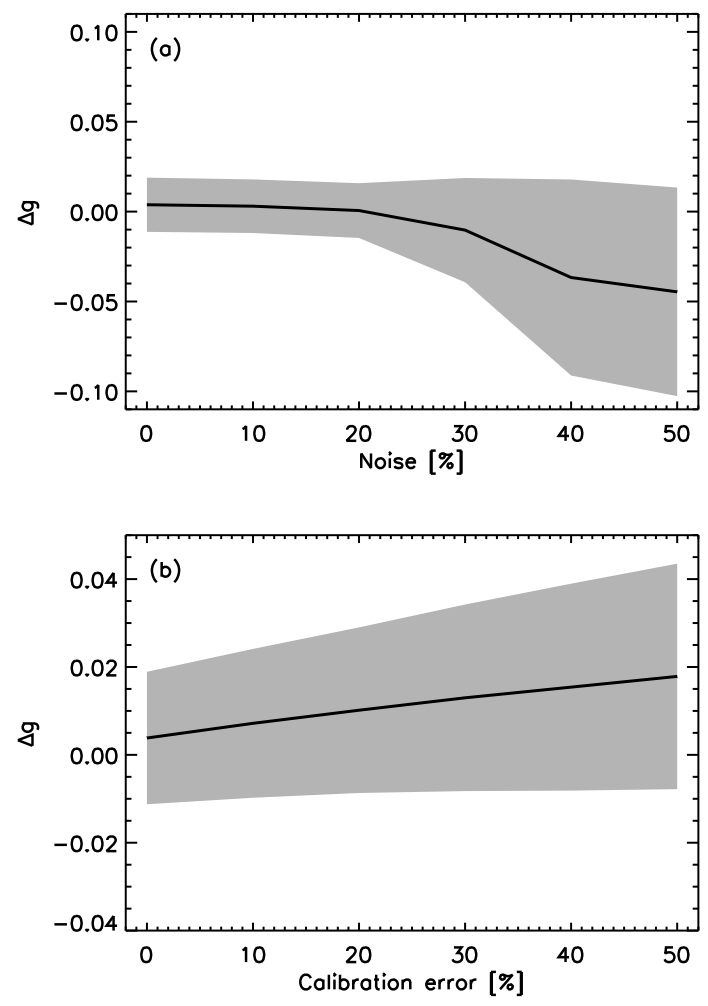

Fig. 10. Dependence of mean bias and standard deviation of retrieved asymmetry parameters from simulated data assuming various complex habits on noise level (a) and calibration error (b). See text for details.

only offsets are added to the polarized reflectances, and an equivalent negative bias trend is obtained when negative offsets are applied to the simulated data (not shown).

The range of scattering angles observed by an instrument depends on the instrument viewing angle range and the solar and relative azimuth angles. The previous analysis assumes scattering angles between $100^{\circ}$ and $165^{\circ}$ to be available. Figure 11a illustrates the performance of the proposed method when narrower scattering angle ranges are available. All considered scattering angle ranges are centered on $132.5^{\circ}$. Figure 11a shows the bias is nearly unaffected by the available scattering angle range. The standard deviation, however, does substantially increase with decreasing angular range, but this is mostly owing to an increasing underestimation of only the asymmetry parameters of pristine individual plates, which represent a small subset of the simulated dataset and therefore do not affect the mean bias substantially. When the available scattering angle range is below $25^{\circ}$, also the asymmetry parameters of aggregates of plates are substantially underestimated, leading to a greater increase in the standard deviation.

As discussed above, these simulations are based on the RSP instrument profile with a relatively dense angular sampling (84 samples at $\sim 0.8^{\circ}$ intervals). Figure $11 \mathrm{~b}$ shows 

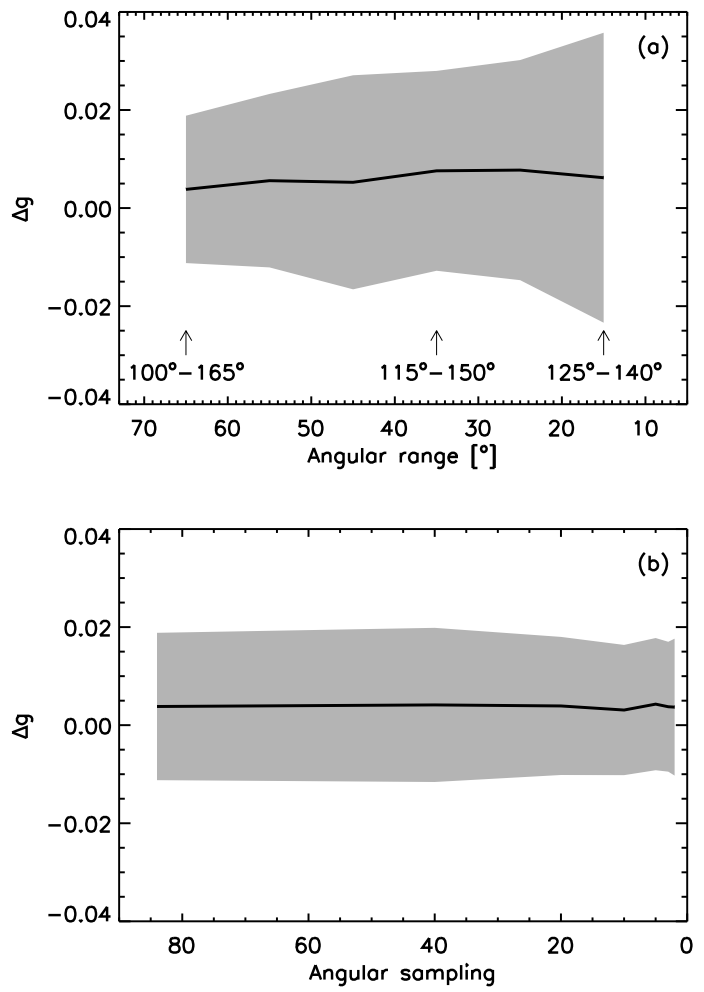

Fig. 11. As Fig. 10 but showing dependence of results on angular range (a) and number of scattering angles sampled (b). In (a), maximum and minimum values of the included scattering angles for three example angular ranges are indicated. See text for details.

retrieval results for simulations with decreasing amount of roughly angular equidistant samples available in the 100$160^{\circ}$ scattering angle range. Interestingly, the results are little affected by angular sampling, even when only 2 samples (at $100^{\circ}$ and $160^{\circ}$ ) are available. Similar results are obtained for simulated measurements assuming habit mixtures and bullet rosettes, although some substantial increase in standard deviation is observed when measurements are degraded from 3 to 2 samples in the case of bullet rosettes (not shown).

The results shown in Figs. 10 and 11 indicate that the proposed method can be applied to measurements of other available instruments, such as POLDER, which have a more limited angular sampling and range and a possibly stronger noise contribution and calibration uncertainties than the RSP.

\section{Conclusions}

This first part of a two-part paper uses simulated measurements to evaluate, to the best our knowledge, the first remote sensing method of inferring the asymmetry parameter of ice clouds. We demonstrate that multi-directional polarized reflectance measurements at visible or near-infrared wavelengths contain exploitable information about the aspect ratio and microscale surface roughness of components of ice crystals, which, in turn, determine the ice crystal asymmetry parameter. By assuming individual, randomly oriented hexagonal columns and plates to be adequate proxies of more complex ice crystals occurring in most natural clouds, ice cloud asymmetry parameters are inferred by matching observed multi-directional polarized reflectance measurements to a look-up table of simulated polarized reflectances for columns and plates with varying aspect ratios and roughness parameters. The asymmetry parameter of the hexagonal particle that leads to the best fit with the measurements is considered the retrieved value.

The application of the method is demonstrated using simulated measurements of clouds consisting of first only bullet rosettes, then other complex habits and finally their mixtures. Instrument characteristics of the airborne Research Scanning Polarimeter (RSP) are assumed for the simulated measurements. Generally, asymmetry parameters of the ice crystals and mixtures assumed in the simulated measurements are retrieved to within $5 \%$, or about 0.04 in absolute terms. Most retrieved values are biased high, especially for bullet rosettes. Since polarized reflectances depend on cloud optical thickness for clouds with $\tau_{\text {cloud }} \lesssim 5$, cloud optical thickness needs to be retrieved simultaneously with the asymmetry parameter for such clouds. For $\tau_{\text {cloud }}>5$, the true cloud optical thickness is not required to retrieve the asymmetry parameter. A sensitivity study shows that the proposed method is largely independent of calibration errors, range and sampling density of scattering angles and random noise in the measurements.

Our results demonstrate that the proposed approach to retrieve asymmetry parameters of ice clouds can be applied to RSP measurements and other current and past instruments, such as the satellite-based POLDER instruments and the airborne Multiangle SpectroPolarimetric Imager (AirMSPI, Diner et al., 2007), as well as on those of possible future instruments, such as the next-generation POLDER instruments (3MI), APS (Mishchenko et al., 2007), MSPI (Diner et al., 2007) and SPEX (van Harten et al., 2011). Furthermore, the method can be easily adapted to degree of linear polarization measurements obtained by future dual-polarization polar nephelometers that are capable of sampling ice clouds.

A single uniform cloud layer is assumed in this study. Possible issues attributable to vertical inhomogeneities will be discussed in Part 2 of this two-part paper and will be addressed in future studies using realistic cloud resolving model simulations. In the case of optically thin ice clouds overlying liquid clouds, the method is not expected to be applicable to measurements in the solar channels since the strong polarization by the liquid clouds would overwhelm the signal (e.g., van Diedenhoven et al., 2012). However, application to polarization measurements in wavelength bands that include strong water vapor absorption, such as the $1.88 \mu \mathrm{m}$ and $1.38 \mu \mathrm{m}$ bands in the RSP and APS designs, respectively, allow the retrieval of ice crystal asymmetry parameters of subvisual cirrus or thin cirrus over liquid clouds because these measurements are virtually unaffected by the 
underlying surface or lower liquid clouds, as demonstrated by Ottaviani et al. (2012a).

Application of the presented approach to the available POLDER data (and future satellite data) has the potential to provide a global database of ice cloud asymmetry parameter that may substantially reduce uncertainties in radiative properties in climate models and improve the retrieval of other ice cloud properties, such as ice crystal sizes and cloud optical thickness. Furthermore, when combined with other observations, possible correlations between retrieved asymmetry parameters and cloud type, cloud-top temperature, ice crystal size or aerosol populations may be deduced in order to improve our understanding of ice cloud formation processes under varying conditions.

Acknowledgements. This material is based upon work supported by the NASA ROSES program under grant number NNX11AG81G and by the NASA Radiation Science Program managed by Hal Maring in support of the SEAC4RS field experiment.

Edited by: A. Kokhanovsky

\section{References}

Auriol, F., Gayet, J.-F., Febvre, G., Jourdan, O., Labonnote, L., and Brogniez, G.: In situ observation of cirrus scattering phase functions with $22^{\circ}$ and $46^{\circ}$ halos: cloud field study on 19 February 1998., J. Atmos. Sci., 58, 3376-3390, doi:10.1175/15200469(2001)058<3376:ISOOCS > 2.0.CO;2, 2001.

Baran, A. J.: A review of the light scattering properties of cirrus, J. Quant. Spectrosc. Ra., 110, 1239-1260, doi:10.1016/j.jqsrt.2009.02.026, 2009.

Baran, A. J. and C.-Labonnote, L.: On the reflection and polarisation properties of ice cloud, J. Quant. Spectrosc. Ra., 100, 41-54, 2006.

Baran, A. J., Shcherbakov, V. N., Baker, B. A., Gayet, J. F., and Lawson, R. P.: On the scattering phase-function of nonsymmetric ice-crystals, Q. J. Roy. Meteorol. Soc., 131, 26092616, doi:10.1256/qj.04.137, 2005.

Baum, B. A., Heymsfield, A. J., Yang, P., and Bedka, S. T.: Bulk scattering properties for the remote sensing of ice clouds, Part I: Microphysical data and models, J. Appl. Meteorol., 44, 1885, doi:10.1175/JAM2308.1, 2005a.

Baum, B. A., Yang, P., Heymsfield, A. J., Platnick, S., King, M. D., $\mathrm{Hu}$, Y. X., and Bedka, S. M.: Bulk scattering properties for the remote sensing of ice clouds, Part II: Narrowband models, J. Appl. Meteorol., 44, 1896-1911, 2005 b.

Baum, B. A., Yang, P., Hu, Y.-X., and Feng, Q.: The impact of ice particle roughness on the scattering phase matrix, J. Quant. Spectrosc. Ra., 111, 2534-2549, doi:10.1016/j.jqsrt.2010.07.008, 2010.

Baum, B. A., Yang, P., Heymsfield, A. J., Schmitt, C. G., Xie, Y., Bansemer, A., Hu, Y.-X., and Zhang, Z.: Improvements in shortwave bulk scattering and absorption models for the remote sensing of ice clouds, J. Appl. Meteorol. Clim., 50, 1037-1056, doi:10.1175/2010JAMC2608.1, 2011.
Bi, L., Yang, P., Kattawar, G. W., Baum, B. A., Hu, Y. X., Winker, D. M., Brock, R. S., and Lu, J. Q.: Simulation of the color ratio associated with the backscattering of radiation by ice particles at the wavelengths of 0.532 and 1.064 micron, J. Geophys. Res., 114, D00H08, doi:10.1029/2009JD011759, 2009.

Bréon, F.-M. and Dubrulle, B.: Horizontally oriented plates in clouds, J. Atmos. Sci., 61, 2888-2898, doi:10.1175/JAS-3309.1, 2004.

C.-Labonnote, L., Brogniez, G., Doutriaux-Boucher, M., Buriez, J., Gayet, J., and Chepfer, H.: Modeling of light scattering in cirrus clouds with inhomogeneous hexagonal monocrystals. Comparison with in-situ and ADEOS-POLDER measurements, Geophys. Res. Lett., 27, 113-116, doi:10.1029/1999GL010839, 2000.

Cairns, B., Russell, E. E., and Travis, L. D.: Research scanning polarimeter: calibration and ground-based measurements, Proc. SPIE, 3754, 186-196, 1999.

Cairns, B., Russell, E. E., LaVeigne, J. D., and Tennant, P. M. W.: Research scanning polarimeter and airborne usage for remote sensing of aerosols, Proc. SPIE, 5158, 33-44, doi:10.1117/12.518320, 2003.

Chepfer, H.: Cirrus clouds' microphysical properties deduced from POLDER observations, J. Quant. Spectrosc. Ra., 60, 375-390, doi:10.1016/S0022-4073(98)00013-2, 1998.

Chepfer, H., Goloub, P., Riedi, J., De Haan, J., Hovenier, J., and Flamant, P.: Ice crystal shapes in cirrus clouds derived from POLDER/ADEOS-1, J. Geophys. Res, 106, 7955-7966, 2001.

Chowdhary, J., Cairns, B., Waquet, F., Knobelspiesse, K., Ottaviani, M., Redemann, J., Travis, L., and Mishchenko, M.: Sensitivity of multiangle, multispectral polarimetric remote sensing over open oceans to water-leaving radiance: Analyses of RSP data acquired during the MILAGRO campaign, Remote Sens. Environ., 118, 284-308, doi:10.1016/j.rse.2011.11.003, 2012.

Coakley, J. A. J. and Chylek, P.: The two-stream approximation in radiative transfer: including the angle of the incident radiation, $\mathrm{J}$. Atmos. Sci., 32, 409-418, 1975.

De Haan, J., Bosma, P., and Hovenier, J.: The adding method for multiple scattering calculations of polarized light, Astron. Astrophys., 183, 371-391, 1987.

Diner, D. J., Davis, A., Hancock, B., Gutt, G., Chipman, R. A., and Cairns, B.: Dual-photoelastic-modulator-based polarimetric imaging concept for aerosol remote sensing, Appl. Optics, 46, 8428, doi:10.1364/AO.46.008428, 2007.

Fougnie, B., Bracco, G., Lafrance, B., Ruffel, C., Hagolle, O., and Tinel, C.: PARASOL in-flight calibration and performance, Appl. Optics, 46, 5435-5451, 2007.

Francis, P. N., Jones, A., Saunders, R. W., Shine, K. P., Slingo, A., and Sun, Z.: An observational and theoretical study of the radiative properties of cirrus: some results from ICE'89, Q. J. Roy. Meteorol. Soc., 120, 809-848, doi:10.1002/qj.49712051804, 1994.

Fu, Q.: A new parameterization of an asymmetry factor of cirrus clouds for climate models, J. Atmos. Sci., 64, 4140, doi:10.1175/2007JAS2289.1, 2007.

$\mathrm{Fu}$, Q. and Liou, K. N.: Parameterization of the radiative properties of cirrus clouds, J. Atmos. Sci., 50, 2008-2025, doi:10.1175/1520-0469(1993)050<2008:POTRPO>2.0.CO;2, 1993. 
Fu, Q., Yang, P., and Sun, W. B.: An accurate parameterization of the infrared radiative properties of cirrus clouds for climate models, J. Climate, 11, 2223-2237, doi:10.1175/15200442(1998)011<2223:AAPOTI>2.0.CO;2, 1998.

Garrett, T. J.: Observational quantification of the optical properties of cirrus cloud, in: Light Scattering Reviews 3, Springer, Berlin, Heidelberg, 3-26, doi:10.1007/978-3-540-48546-9, 2008.

Garrett, T. J., Hobbs, P. V., and Gerber, H.: Shortwave, singlescattering properties of arctic ice clouds, J. Geophys. Res., 106, 15155-15172, doi:10.1029/2000JD900195, 2001.

Garrett, T. J., Gerber, H., Baumgardner, D. G., Thohy, C. H., and Weinstock, E. M.: Small, highly reflective ice crystals in low-latitude cirrus, Geophys. Res. Lett., 30, 10-13, doi:10.1029/2003GL018153, 2003.

Garrett, T. J., Navarro, B. C., Twohy, C. H., Jensen, E. J., Baumgardner, D. G., Bui, P. T., Gerber, H., Herman, R. L., Heymsfield, A. J., Lawson, P., Minnis, P., Nguyen, L., Poellot, M., Pope, S. K., Valero, F. P. J., and Weinstock, E. M.: Evolution of a Florida cirrus anvil, J. Atmos. Sci., 62, 2352, doi:10.1175/JAS3495.1, 2005.

Gayet, J. F., Crépel, O., Fournol, J. F., and Oshchepkov, S.: A new airborne polar Nephelometer for the measurements of optical and microphysical cloud properties. Part I: Theoretical design, Ann. Geophys., 15, 451-459, doi:10.1007/s00585-997-0451-1, 1997.

Gayet, J.-F., Shcherbakov, V., Mannstein, H., Minikin, A., Schumann, U., Ström, J., Petzold, A., Ovarlez, J., and Immler, F.: Microphysical and optical properties of midlatitude cirrus clouds observed in the Southern Hemisphere during INCA, Q. J. Roy. Meteorol. Soc., 132, 2719-2748, doi:10.1256/qj.05.162, 2006.

Gayet, J.-F., Mioche, G., Bugliaro, L., Protat, A., Minikin, A., Wirth, M., Dörnbrack, A., Shcherbakov, V., Mayer, B., Garnier, A., and Gourbeyre, C.: On the observation of unusual high concentration of small chain-like aggregate ice crystals and large ice water contents near the top of a deep convective cloud during the CIRCLE-2 experiment, Atmos. Chem. Phys., 12, 727-744, doi:10.5194/acp-12-727-2012, 2012.

Gerber, H., Takano, Y., Garrett, T. J., and Hobbs, P. V.: Nephelometer measurements of the asymmetry parameter, volume extinction coefficient, and backscatter ratio in arctic clouds, J. Atmos. Sci., 57, 3021-3034, 2000.

Hansen, J. E. and Travis, L. D.: Light scattering in planetary atmospheres, Space Sci. Rev., 16, 527-610, doi:10.1007/BF00168069, 1974.

Hartmann, D. L., Ockert-Bell, M. E., and Michelsen, M. L.: The effect of cloud type on Earth's energy balance: global analysis, J. Climate, 5, 1281-1304, doi:10.1175/15200442(1992)005<1281:TEOCTO>2.0.CO;2, 1992.

Hess, M., Koelemeijer, R. B., and Stammes, P.: Scattering matrices of imperfect hexagonal ice crystals, J. Quant. Spectrosc. Ra., 60, 301-308, doi:10.1016/S0022-4073(98)00007-7, 1998.

Heymsfield, A. J., Bansemer, A., Field, P. R., Durden, S. L., Stith, J. L., Dye, J. E., Hall, W., and Grainger, C. A.: Observations and parameterizations of particle size distributions in deep tropical cirrus and stratiform precipitating clouds: results from in situ observations in TRMM field campaigns, J. Atmos. Sci., 59, 3457-3491, doi:10.1175/15200469(2002)059<3457:OAPOPS>2.0.CO;2, 2002.
Iaquinta, J., Isaka, H., and Personne, P.: Scattering phase function of bullet rosette ice crystals, J. Atmos. Sci., 52, 1401-1413, doi:10.1175/1520-0469(1995)052<1401:SPFOBR > 2.0.CO;2, 1995.

Ishimoto, H., Masuda, K., Mano, Y., Orikasa, N., and Uchiyama, A.: Irregularly shaped ice aggregates in optical modeling of convectively generated ice clouds, J. Quant. Spectrosc. Ra., 632-643, doi:10.1016/j.jqsrt.2012.01.017, 2012.

King, M. D.: Determination of the scaled optical thickness of clouds from reflected solar radiation measurements, J. Atmos. Sci., 44, 1734-1751, doi:10.1175/15200469(1987)044<1734:DOTSOT>2.0.CO;2, 1987.

Knap, W. H., Labonnote, L. C., Brogniez, G., and Stammes, P.: Modeling total and polarized reflectances of ice clouds: evaluation by means of POLDER and ATSR-2 measurements, Appl. Optics, 44, 4060, doi:10.1364/AO.44.004060, 2005.

Korolev, A. V., Emery, E. F., Strapp, J. W., Cober, S. G., Isaac, G. A., Wasey, M., and Marcotte, D.: Small ice particles in tropospheric clouds: fact or artifact? Airborne icing instrumentation evaluation experiment, B. Am. Meteorol. Soc., 92, 967-973, doi:10.1175/2010BAMS3141.1, 2011.

Lawson, R. P., Baker, B., Pilson, B., and Mo, Q.: In situ observations of the microphysical properties of wave, cirrus, and anvil clouds, Part II: Cirrus clouds, J. Atmos. Sci., 63, 3186, doi:10.1175/JAS3803.1, 2006.

Lindsey, D. T. and Grasso, L.: An effective radius retrieval for thick ice clouds using GOES, J. Appl. Meteorol. Clim., 1222-1231, doi:10.1175/2007JAMC1612.1, 2009.

Litvinov, P., Hasekamp, O., Cairns, B., and Mishchenko, M.: Reflection models for soil and vegetation surfaces from multipleviewing angle photopolarimetric measurements, J. Quant. Spectrosc. Rad. Transf., 529-539, 2010.

Liu, L., Mishchenko, M. I., Cairns, B., Carlson, B. E., and Travis, L. D.: Modeling single-scattering properties of small cirrus particles by use of a size-shape distribution of ice spheroids and cylinders, J. Quant. Spectrosc. Ra., 101, 488-497, doi:10.1016/j.jqsrt.2006.02.040, 2006.

Macke, A., Mueller, J., and Raschke, E.: Single scattering properties of atmospheric ice crystals, J. Atmos. Sci., 53, 2813-2825, 1996.

Masuda, K., Ishimoto, H., and Takashima, T.: Retrieval of cirrus optical thickness and ice-shape information using total and polarized reflectance from satellite measurements, J. Quant. Spectrosc. Ra., 75, 39-51, doi:10.1016/S0022-4073(01)002916, 2002.

Minnaert, M. G. J.: The Nature of Light \& Colour in the Open Air, Dover, New York, 1954.

Mishchenko, M. I. and Macke, A.: How Big Should Hexagonal Ice Crystals be to Produce Halos?, Appl. Optics, 38, 1626-1629, 1999.

Mishchenko, M. I., Cairns, B., Kopp, G., Schueler, C. F., Fafaul, B. A., Hansen, J. E., Hooker, R. J., Itchkawich, T., Maring, H. B., and Travis, L. D.: Accurate monitoring of terrestrial aerosols and total solar irradiance: introducing the glory mission, B. Am. Meteorol. Soc., 88, 677, doi:10.1175/BAMS-88-5-677, 2007.

Mitchell, D. L.: Evolution of snow-size spectra in cyclonic storms, Part II: Deviations from the exponential form, J. Atmos. Sci., 48, 1885-1899, doi:10.1175/15200469(1991)048<1885:EOSSSI > 2.0.CO;2, 1991. 
Mitchell, D. and Arnott, W.: A model predicting the evolution of ice particle size spectra and radiative properties of cirrus clouds, Part II: Dependence of absorption and extinction on ice crystal morphology, J. Atmos. Sci., 13, 817-832, doi:10.1175/15200469(1994)051<0817:AMPTEO>2.0.CO;2, 1994.

Mitchell, D. L., Liu, Y., and Macke, A.: Modeling cirrus clouds, Part II: Treatment of radiative properties, J. Atmos. Sci., 53, 2967-2988, doi:10.1175/15200469(1996)053<2967:MCCPIT>2.0.CO;2, 1996.

Nakajima, T. and King, M. D.: Determination of the optical thickness and effective particle radius of clouds from reflected solar radiation measurements, I - Theory, J. Atmos. Sci., 47, 1878-1893, doi:10.1175/15200469(1990)047<1878:DOTOTA > 2.0.CO;2, 1990.

Nakajima, T. Y. and Tanaka, M.: Algorithms for radiative intensity calculations in moderately thick atmospheres using a truncation approximation, J. Quant. Spectrosc. Ra., 40, 51-69, doi:10.1016/0022-4073(88)90031-3, 1988.

Nousiainen, T., Lindqvist, H., McFarquhar, G. M., and Um, J.: Small irregular ice crystals in tropical cirrus, J. Atmos. Sci., 68, 2614-2627, doi:10.1175/2011JAS3733.1, 2011.

Ottaviani, M., Cairns, B., Chowdhary, J., van Diedenhoven, B., Knobelspiesse, K., Hostetler, C., Ferrare, R., Burton, S., Hair, J., Obland, M., and Rogers, R.: Polarimetric retrievals of surface and cirrus clouds properties in the region affected by the deepwater horizon oil spill, Remote Sens. Environ., 121, 389-403, doi:10.1016/j.rse.2012.02.016, 2012a.

Ottaviani, M., Cairns, B., Ferrare, R., and Rogers, R.: Iterative atmospheric correction scheme and the polarization color of alpine snow, J. Quant. Spectrosc. Ra., 113, 789-804, doi:10.1016/j.jqsrt.2012.03.014, 2012b.

Platnick, S., King, M., Ackerman, S., Menzel, W., Baum, B., Riedi, J., and Frey, R.: The MODIS cloud products: algorithms and examples from terra, IEEE T. Geosci. Remote, 41, 459-473, doi:10.1109/TGRS.2002.808301, 2003.

Platt, C. M. R., Reynolds, D. W., and Abshire, N. L.: Satellite and Lidar observations of the albedo, emittance and optical depth of cirrus compared to model calculations, Mon. Weather Rev., 108, 195-204, doi:10.1175/15200493(1980)108<0195:SALOOT>2.0.CO;2, 1980.

Rodgers, C.: Inverse methods for atmospheric sounding: theory and practice, ISBN-13: 978-9810227401, World Scientific, Singapore, 2000.

Roebeling, R. A., Feijt, A. J., and Stammes, P.: Cloud property retrievals for climate monitoring: implications of differences between Spinning Enhanced Visible and Infrared Imager (SEVIRI) on METEOSAT-8 and Advanced Very High Resolution Radiometer (AVHRR) on NOAA-17, J. Geophys. Res., 111, D20210, doi:10.1029/2005JD006990, 2006.

Rolland, P., Liou, K. N., King, M. D., Tsay, S. C., and McFarquhar, G. M.: Remote sensing of optical and microphysical properties of cirrus clouds using Moderate-Resolution Imaging Spectroradiometer channels: methodology and sensitivity to physical assumptions, J. Geophys. Res., 105, 11721-11738, doi:10.1029/2000JD900028, 2000.

Sassen, K., Zhu, J., and Benson, S.: Midlatitude cirrus cloud climatology from the facility for atmospheric remote sensing, IV. Optical displays, Appl. Optics, 42, 332, doi:10.1364/AO.42.000332, 2003.
Soden, B. J. and Held, I. M.: An assessment of climate feedbacks in coupled ocean-atmosphere models, J. Climate, 19, 3354, doi:10.1175/JCLI3799.1, 2006.

Stackhouse Jr., P. W. and Stephens, G. L.: A theoretical and observational study of the radiative properties of cirrus: results from FIRE 1986, J. Atmos. Sci., 48, 2044-2059, doi:10.1175/15200469(1991)048<2044:ATAOSO > 2.0.CO;2, 1991.

Stephens, G. L., Tsay, S.-C., Stackhouse Jr., P. W., and Flatau, P. J.: The relevance of the microphysical and radiative properties of cirrus clouds to climate and climatic feedback, J. Atmos. Sci., 47, 1742-1754, 1990.

Sun, W., Loeb, N., and Yang, P.: On the retrieval of ice cloud particle shapes from POLDER measurements, J. Quant. Spectrosc. Ra., 101, 435-447, doi:10.1016/j.jqsrt.2006.02.071, 2006.

Um, J. and McFarquhar, G. M.: Single-scattering properties of aggregates of bullet rosettes in cirrus, J. Appl. Meteorol. Clim., 46, 757-775, doi:10.1175/JAM2501.1, 2007.

Um, J. and McFarquhar, G. M.: Single-scattering properties of aggregates of plates, Q. J. Roy. Meteorol. Soc, 135, 291-304, doi:10.1002/qj.378, 2009.

Um, J. and McFarquhar, G. M.: Dependence of the single-scattering properties of small ice crystals on idealized shape models, Atmos. Chem. Phys., 11, 3159-3171, doi:10.5194/acp-11-31592011, 2011.

van de Hulst, H. C.: Light Scattering by Small Particles, Dover Publications, New York, 1957.

van Diedenhoven, B., Fridlind, A. M., Ackerman, A. S., and Cairns, B.: Evaluation of hydrometeor phase and ice properties in cloud-resolving model simulations of tropical deep convection using radiance and polarization measurements, J. Atmos. Sci., in press, doi:10.1175/JAS-D-11-0314.1, 2012.

van Harten, G., Snik, F., Rietjens, J. H. H., Smit, J. M., de Boer, J., Diamantopoulou, R., Hasekamp, O. P., Stam, D. M., Keller, C. U., Laan, E. C., Verlaan, A. L., Vliegenthart, W. A., ter Horst, R., Navarro, R., Wielinga, K., Hannemann, S., Moon, S. G., and Voors, R.: Prototyping for the Spectropolarimeter for Planetary EXploration (SPEX): calibration and sky measurements, in: SPIE Conf. Series, Vol. 8160, 81600Z-1-81600Z12, doi:10.1117/12.893741, 2011.

Vogelmann, A. M. and Ackerman, T. P.: Relating cirrus cloud properties to observed fluxes: a critical assessment, J. Atmos. Sci., 52, 4285-4301, doi:10.1175/15200469(1995)052<4285:RCCPTO>2.0.CO;2, 1995.

Waliser, D. E., Li, J.-L. F., Woods, C. P., Austin, R. T., Bacmeister, J., Chern, J., Del Genio, A., Jiang, J. H., Kuang, Z., Meng, H., Minnis, P., Platnick, S., Rossow, W. B., Stephens, G. L., SunMack, S., Tao, W.-K., Tompkins, A. M., Vane, D. G., Walker, C., and Wu, D.: Cloud ice: a climate model challenge with signs and expectations of progress, J. Geophys. Res., 114, D00A21, doi:10.1029/2008JD010015, 2009.

Warren, S. G. and Brandt, R. E.: Optical constants of ice from the ultraviolet to the microwave: a revised compilation, J. Geophys. Res., 113, D14220, doi:10.1029/2007JD009744, 2008.

Wiscombe, W. J.: The Delta-M method: rapid yet accurate radiative flux calculations for strongly asymmetric phase functions, J. Atmos. Sci., 34, 1408-1422, doi:10.1175/15200469(1977)034<1408:TDMRYA>2.0.CO;2, 1977. 
Xie, Y., Yang, P., Kattawar, G. W., Baum, B. A., and Hu, Y.: Simulation of the optical properties of plate aggregates for application to the remote sensing of cirrus clouds, Appl. Optics, 50, 1065, doi:10.1364/AO.50.001065, 2011.

Yang, P. and Fu, Q.: Dependence of ice crystal optical properties on particle aspect ratio, J. Quant. Spectrosc. Ra., 110, 1604-1614, doi:10.1016/j.jqsrt.2009.03.004, 2009.

Yang, P. and Liou, K.: Single-scattering properties of complex ice crystals in terrestrial atmosphere, Contr. Atmos. Phys., 71, 223248, 1998.

Yang, P., Liou, K., Wyser, K., and Mitchell, D.: Parameterization of scattering and absorption properties of individual ice crystals, J. Geophys. Res., 105, 4699-4718, 2000.

Yang, P., Hong, G., Kattawar, G., Minnis, P., and Hu, Y.: Uncertainties associated with the surface texture of ice particles in satellite-based retrieval of cirrus clouds: Part II - Effect of particle surface roughness on retrieved cloud optical thickness and effective particle size, IEEE T. Geosci. Remote, 46, 1948-1957, doi:10.1109/TGRS.2008.916472, 2008a.

Yang, P., Kattawar, G., Hong, G., Minnis, P., and Hu, Y.: Uncertainties associated with the surface texture of ice particles in satellitebased retrieval of cirrus clouds - Part I: Single-scattering properties of ice crystals with surface roughness, IEEE T. Geosci. Remote, 46, 1940-1947, doi:10.1109/TGRS.2008.916471, 2008b.
Yang, P., Zhang, Z., Kattawar, G. W., Warren, S. G., Baum, B. A., Huang, H.-L., Hu, Y. X., Winker, D., and Iaquinta, J.: Effect of cavities on the optical properties of bullet rosettes: implications for active and passive remote sensing of ice cloud properties, J. Appl. Meteorol. Clim., 47, 2311-2330, doi:10.1175/2008JAMC1905.1, 2008c.

Yang, P., Bi, L., Baum, B. A., Liou, K.-N., Kattawar, G. W., Mishchenko, M. I., and Cole, B.: Spectrally consistent scattering, absorption, and polarization properties of atmospheric ice crystals at wavelengths from $0.2 \mu \mathrm{m}$ to $100 \mu \mathrm{m}$, J. Atmos. Sci., online first: doi:10.1175/JAS-D-12-039.1, 2012.

Zhang, Z., Yang, P., Kattawar, G. W., Tsay, S.-C., Baum, B. A., Hu, Y., Heymsfield, A. J., and Reichardt, J.: Geometrical-optics solution to light scattering by droxtal ice crystals, Appl. Optics, 43, 2490-2499, 2004.

Zhang, Z., Yang, P., Kattawar, G., Riedi, J., Labonnote, L. C., Baum, B. A., Platnick, S., and Huang, H.-L.: Influence of ice particle model on satellite ice cloud retrieval: lessons learned from MODIS and POLDER cloud product comparison, Atmos. Chem. Phys., 9, 7115-7129, doi:10.5194/acp-9-7115-2009, 2009.

Zhou, C., Yang, P., Dessler, A. E., Hu, Y., and Baum, B. A.: Study of horizontally oriented ice crystals with CALIPSO observations and comparison with Monte Carlo radiative transfer simulations, J. Appl. Meteor. Climatol., 59, 1426-1439, doi:10.1175/JAMCD-11-0265.1, 2012. 